\title{
Saying Good-bye to Practice and Patients
}

Ann Fam Med 2011;9:iii. doi:10.1370/afm.1259.

The Annals of Family Medicine encourages readers to develop a learning community of those seeking to improve health care and health through enhanced primary care. You can participate by conducting a RADICAL journal club and sharing the results of your discussions in the Annals online discussion for the featured articles. RADICAL is an acronym for Read, Ask, Discuss, Inquire, Collaborate, Act, and Learn. The word radical also indicates the need to engage diverse participants in thinking critically about important issues affecting primary care and then acting on those discussions. ${ }^{1}$

\section{HOW IT WORKS}

In each issue, the Annals selects an article or articles and provides discussion tips and questions. We encourage you to take a RADICAL approach to these materials and to post a summary of your conversation in our online discussion. (Open the article online and click on "TRACK Comments: Submit a response.") You can find discussion questions and more information online im at: http://www.AnnFamMed.org/site/AJC/.

\section{CURRENT SELECTION}

\section{Article for Discussion}

Shorer Y, Biderman A, Levy A, et al. Family physicians leaving their clinic-the Balint group as an opportunity to say good-bye. Ann Fam Med. 2011;9(6):549-551.

\section{Discussion Tips}

This issue's Annals Journal Club tells the story of how a rather ordinary beginning to a Balint group led to a profound insight that changed how a physician left her practice with mindfulness rather than disregard. This essay provides a chance for those who may be facing departure from their own practice to consider the implications for themselves, their colleagues, and their patients.

\section{Discussion Questions}

- What topics are addressed by the article?

- What forums do you have for individual and group reflection and growth from your practice?

- In this essay, how does the topic for the Balint group discussion come up?

- What aspects of the group process allow the departing physician's flash insight to emerge?

- How realistic and relevant does the authors' analysis of the Balint process appear? What is missing? What other insights do you have?

- How does the physician's insight relate to your own experiences of departure or anticipated experiences of leaving a practice?

- How does the experience of this Balint group event relate to a prior Annals article ${ }^{2}$ and journal club ${ }^{3}$ that examined the effects of Balint group participation on practicing physicians?

- After reading this article, what forums would you suggest for individual and group reflection and growth from your practice and how might you set them up?

- How might you prepare yourself and your practice partners for your impending departure from practice? For other changes? ${ }^{4}$ What internal and external work will you need to do? ${ }^{5}$

\section{References}

1. Stange KC, Miller WL, McLellan LA, et al. Annals Journal Club: It's time to get RADICAL. Ann Fam Med. 2006;4(3):196-197.

2. Kjeldmand D, Holmström I. Balint groups as a means to increase job satisfaction and prevent burnout among general practitioners. Ann Fam Med. 2008;6(2):138-145.

3. Annals Journal Club: Balint groups and 'the joy of being a doctor.' Ann Fam Med. 2008;6(2):iii.

4. Loxterkamp D. A change will do you good. Ann Fam Med. 2009; 7(3):261-263.

5. Easwaran E. Conquest of Mind. 2nd ed. Petaluma, GA: Nilgiri Press; 1997. 